\title{
UGT1a1 Gene Mutations in a Tibetan Patient with Crigler-Najjar SyndromeType II - Case Report and Literature Review
}

\author{
Li-Bo Yan ${ }^{1}$, Fang He ${ }^{1}$, Hong Tang ${ }^{1 *}$ \\ ${ }^{1}$ Center of Infectious Diseases, West China Hospital, Sichuan University, People's Republic of China
}

Received date: January 11, 2018; Published date: February 05, 2018

*Corresponding author: Hong Tang, Center of Infectious Diseases, West China Hospital of Sichuan University, No. 37 Guo Xue Xiang, Chengdu 610041, People’s Republic of China, Tel: +862885422650; Fax: +862885423052; Email: htang6198@hotmail.com

\begin{abstract}
Crigler-Najjar Syndrome (CNS) is un conjugated hyperbilirubinemia caused by mutations in bilirubin UDP-glucuronosyl transferase (UGT1A1) gene which can transform the un conjugated bilirubin by conjugating it with glucuronic acid. There are two types of CNS.CNS-I is fatal because of the bilirubin encephalopathy combined with severe un conjugated hyperbilirubinaemia, while CNS-II is a moderate form of hyperbilirubinemia and can be treated with phenobarbital therapy. The CNS-II has never been reported in Tibetan population. This is the first reported case of Tibetan patient with CNS-II based on the UGT1A1 gene analysis.
\end{abstract}

Keywords: Crigler-Najjar Syndrome; UGT1A1; Tibetan

Abbreviations: CNS-I: Crigler-Najjar Syndrometype I; CNS-II: Crigler-Najjar Syndrome type II; GS: Gibert Syndrome; UGT1A1: UDPGlucuronosyl Transferase

\section{Introduction}

Crigler-Najjar Syndrome (CNS) is an autosomal recessive hereditary disorder characterized by moderate to severe unconjugated hyperbilirubinemia without hemolysis and caused by a deficiency of bilirubin UDP-glucuronosyltransferase (UGT1A1) enzyme due to mutations of UGT1A1 gene [1]. CNS can be classified into type I or type II based on the hyperbilirubinaemia level and patients' response to phenobarbital treatment. CNS-I is fatal because of the bilirubin encephalopathy with the presence of severe un-conjugated hyperbilirubinaemia. CNS-II is a moderate form of hyperbilirubinemia and patients have good responses to the phenobarbital treatment [2]

\section{Case Presentation}

A 17-year-old Tibetan male presented at the inpatient department with sustained jaundice since his birth. There was no history of fatigability, fever, abdomen pain, pruritus, claycolored stools, or soy-sauce-colored urine. Physical examination identified severe yellowing staining of skin and sclera. There was no pallor, hepatomegaly, splenomegaly, or feature of liver cirrhosis.

The laboratory examination results for blood stool and urine routines were normal. Biochemical analysis of blood showed that total serum bilirubin was 321.3umol/L (conjugated bilirubin 17.6umol/L and un-conjugated bilirubin $303.7 \mathrm{umol} / \mathrm{L}$ ), alanine amino transferase was 25IU/L (normal $50 \mathrm{IU} / \mathrm{L}$ ), aspartate amino transferase was 26IU/L (normal <40 IU/L), alkaline phosphatase was $125 \mathrm{IU} / \mathrm{L}$ (normal <125IU/L), $\gamma$-glutamyl transpeptidase was18IU/L (normal <60 IU/L), and prothrombin time was $11.9 \mathrm{~s}$ (control 12.8s)

There was no evidence of intravascular hemolysis. The diagnostic results were negative for all viral markers including HBsAg, anti-HCV, anti-HEV IgA, anti-HAV IgM, anti-CMV, antiEBV. The testing results with serological antibodies of nuclear, mitochondrial, liver-kidney microsomal and liver cytoplasm were negative too. Serum ceruloplasm in level was $284.0 \mathrm{mg} / \mathrm{L}$. MRI showed no evidence of biliary obstruction and normal liver form. The patient's mother had mild jaundice while his father didn't have any.

Because the patient had the elevated un-conjugated bilirubin but had normal liver function and no evidence of hemolysis, a clinical diagnosis of Gilbert's disease or CNS-II was made. CNSII was more likely because serum bilirubin was $>103 \mu \mathrm{mol} / \mathrm{L}$. Mutation analysis of UGT1A1 gene was carried out for this purpose. 


\section{Mutation Analysis of UGT1A1 Gene}

The direct sequencing of the UGT1A1 gene was reported previously. This patient carried several point mutations on UGT1A1 Gene (c.211G $\rightarrow$ A on exon 1 and c.1456T $\rightarrow$ G on exon $5)$, mutations that changed glycerine to argine and tyrosine to aspartic acid (positions 71 and 486 of the UGT1A1 protein) respectively (Figure 1). The promoter TA repeat region in exon 1 carried normal TA repeats A(TA)6TAA. The combination of homozygous G71R and Y486D mutations in UGT1A1 confirmed the diagnosis of CNS-II.

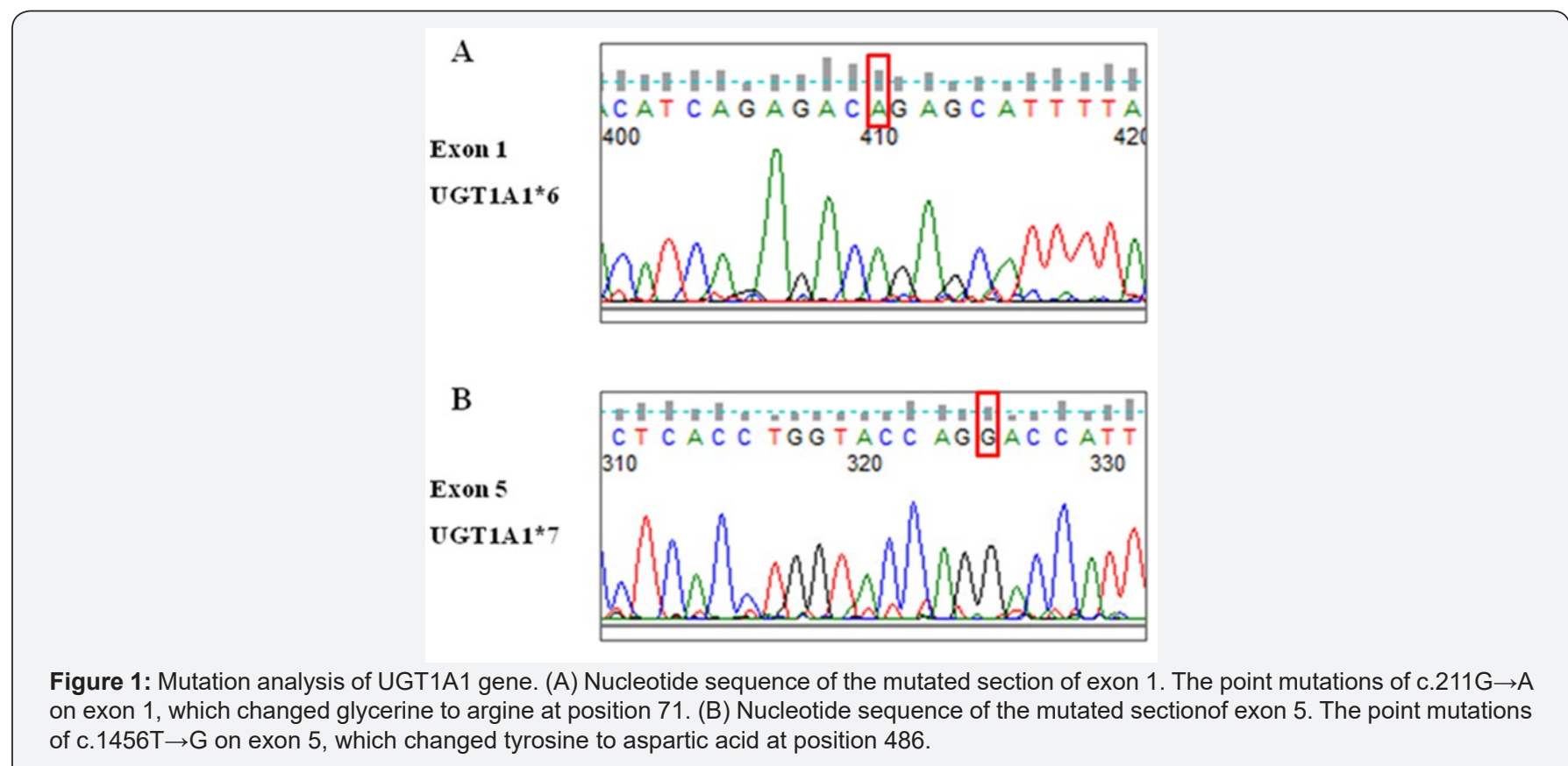

\section{Discussion}

Hereditary hyperbilirubinemias the direct result of genetic defects in enzymes that control the bilirubin metabolism. There are two major types of hereditary hyperbilirubinemias, the unconjugated hyperbilirubinemia such as CNS-I, CNS-II, and Gilbert syndrome (GS) and the conjugated hyperbilirubinemia such as Dubin-Johnson syndrome and Rotor syndrome [3].

CNS-I, CNS-II, GSare familial un-conjugated hyperbilirubinemias resulted from genetic mutations of UGT1A1which transforms the un-conjugated bilirubin in to a nontoxic form with the insertion of one glucuronic acid. Genetic mutations of UGT1A1lead to the absence, severe or moderate reduction of UGT1A1 enzymatic activities (corresponding to CNS-I, CNS-II or GS disease respectively) [4].

The clinical classifications of CNS-I, CNS-II and GS are based on several metrics such as the bilirubin levels, the presence of kernictus, and the response to phenobarbitone. CNS-I patients' bilirubin level is above $342 \mu \mathrm{mol} / \mathrm{L}$ or higher and the patients do not respond to the Phenobarbital treatment due to the complete absence of UGT1A1 enzyme activity. The patients usually die of kernicterus at early ages. There were case reports of liver transplantations for CNS-I patients. CNS-II patients' bilirubin level is in the range of $103-342 \mu \mathrm{mol} / \mathrm{L}$ due to severe deficiency of UGT1A1 enzyme activity (usually less than $10 \%$ of normal activity). This bilirub in level can be cut by more than $30 \%$ after Phenobarbital treatment. GS patients' bilirubin level is usually lower than $103 \mu \mathrm{mol} / \mathrm{L}$ and the patients also respond to Phenobarbital treatment very well. UGT1A1 enzyme activity in those patients is approximately 30 percent of that in normal population.

Crigler-Najjar syndromes are rare diseases, with only 100 cases reported in literatures to date. The incidence of CNS is estimated to be 1 in 1,000,000 births. There were a few cases of CNS-II reported in china [5-7]. Qing Mao's research showed the spectrum ofUGT1A1 mutations in 11 CNS-II patients in China [6]. However, CNS-II case has never been reported in Tibetan population. This is the first such case of Tibetan patient with CNS-II andUGT1A1 gene analysis. The incidence of GS is approximately $3-7 \%$ of adults.

Both CNS and GS are caused by the mutations of UGT1A1 gene, a single gene at chromosome 2q37. UGT1geneconsists of 13 unique alternate first exons (exons 1) and four common exons (exons 2-5) that encode nine function enzymes involved in the transformation of small lipophilic molecules, such as steroids, bilirubin, hormones, and drugs, into water-soluble and excretable metabolites. UGT1A1 is the only enzyme from the glucuronidation pathway that transforms un-conjugated bilirubin into a nontoxic form by attaching one glucuronic acid [8]. Genetic mutations of UGT1A1can lead to the absence, severe 
or moderate reduction of UGT1A1 enzymatic activity, which eventually result in CNS-I, CNS-II and GS, respectively.

The patient in this study was diagnosed with un-conjugated hyperbilirubinemia and had a compound homozygous mutation in the UGT1A1gene (p.G71R and p.Y486D). The promoter region of the gene carried normal TA repeats A(TA)6TAA.The patient was diagnosed as CNS-II based on his medical history and biochemical and genetic analysis. The level of bilirubin fluctuated between $231 \mathrm{umol} / \mathrm{L}$ and $324 \mathrm{umol} / \mathrm{L}$ in this patient, in consistent with the reports that bilirubin levels were always greater than $200 \mu \mathrm{mol} / \mathrm{L}$ for CNS-II patients with compound homozygous mutations (p.G71R and p.Y486D) [6]. The phenotype of this patient was classified as UGT1A1 genotype. Previous study demonstrated that UGT1A1 activity of the heterozygous model of G71R was $60.2 \pm 3.5 \%$ of that for the wild-type model, while UGT1A1activitiesof single homozygous models of G71R and Y486D were $32.2 \pm 1.6 \%$ and $7.6 \pm 0.5 \%$ respectively and those of double homozygous models of G71R and Y486D were6.2 $\pm 1.6 \%$, respectively [9]. The mutation G71R was mild, since it was observed in the homozygous state in Gilbert syndrome. When this mutation was observed in CNS-II, it always came with homozygous Y486D mutation [2].

To date, there were almost 40 reported UGT1A1mutationsrelated to CNS-II. CNS-II diagnosis is usually associated with compound homozygosity or heterozygosity for missense mutations or deletion mutations [10,11]. The compound homozygous mutations (p.G71R and p.Y486D) were the most common mutations in asian CNS-II patients, and were detected in 14 of 27 East Asian patients, while there were detected only in 1 of 58 Caucasian patients, and in 1 of 14 other races including India and Pakistani [6]. Previous study discovered that the mutation rate in coding region of UGT1A1 was higher among Asians than among Caucasians [12]. The mutation in UGT1A1 might be different among different races. Since there was no previously reported data in Tibetan patient with CNS-II, this case would provide a highly valuable reference. The mutations of UGT1A1 in CNS-II were listed in Figure 2.

To date there were almost 50 UGT1A1mutations found to be related to CNS-I. CNS-I is caused by nonsense (or frame-shift) or missense mutations or deletion mutations in both homozygosity and compound heterozygous state [10]. The mutations of UGT1A1 in CNS-I were also listed in Figure 2.

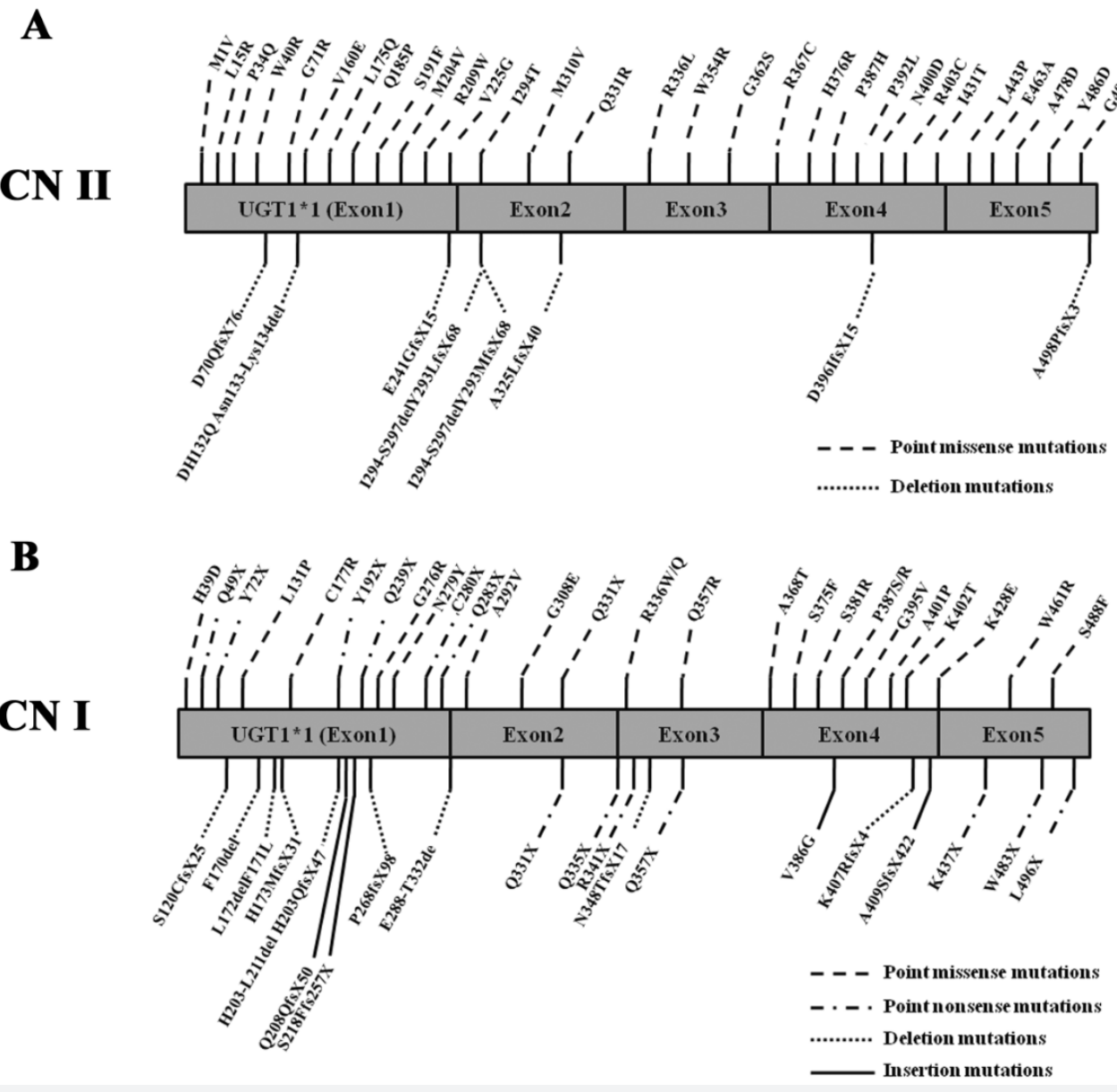

Figure 2: Localization of mutations that affect the gene encoding UDP-glucuronosyl Transferase in patients with Crigler-Najjar syndrome. 
$80 \%$ GS patients were homozygous for the TA insertion in the promoter upstream to the coding sequences. While the normal TATAA element in the promoter has the sequence A(TA)6TAA, the Gilbert-type promoter has the sequence A(TA)7TAA [13]. Many mutations (G71R, P229Getc) reported in the coding sequences of UGT1A1 may also cause mild un-conjugated hyperbilirubinemia, consistent with the clinical diagnosis of Gilbert syndrome [10]. Elı'sio Costa's study suggested that c.-3279T >Gpolymorphism in phenobarbital responsive enhancer module of UGT1A1 gene could be an additional risk factor for the development of GS [14].

In conclusions, this is the first reported case of Tibetan patient with CNS-II based on the UGT1A1 gene analysis despite the compound homozygous mutations (p.G71R and p.Y486D) in UGT1A1 were reported. Mutation analysis confirmed the diagnosis and a definite management would be carried out.

\section{References}

1. Ranjan P, Kohli S, Saxena R, Thakur S (2011) Mutation Analysis in Crigler-Najjar Syndrome Type II-Case Report and Literature Review. J Clin Exp Hepatol 1(3): 204-206.

2. Sampietro M, Iolascon A (1999) Molecular pathology of Crigler-Najjar type I and II and Gilbert's syndromes. Haematologica 84(2): 150-157.

3. Sticova E, Jirsa M (2013) New insights in bilirubin metabolism and their clinical implications. World J Gastroenterol 19(38): 6398-6407.

4. Maruo Y, Topaloglu AK, Takahashi H, Mori A, Iwai M, et al. (2006) Crigler-Najjar syndrome type II caused by a homozygous triple mutation [T-3279G, A(TA)7TAA, and H39D] of UGT1A1. JPediatr Gastroenterol Nutr 42(2): 236-239.

5. Zheng B, Hu G, Yu J, Liu Z (2014) Crigler-Najjar syndrome type II in a Chinese boy resulting from three mutations in the bilirubin uridine 5 '-diphosphate-glucuronosyltransferase (UGT1A1) gene and a family genetic analysis. BMC Pediatr 14:267.
6. Li L, Deng G, Tang Y, Mao Q (2015) Spectrum of UGT1A1 Variations in Chinese Patients with Crigler-Najjar Syndrome Type II. PLoS One 10(5): e0126263.

7. Wu JX, Cheng GY, Huang J (2008) A homozygous mutation in a Chinese man with Crigler-Najjar syndrome type II and a family genetic analysis. J Dig Dis 9(2): 89-94.

8. van Dijk R, Beuers U, Bosma PJ (2015) Gene replacement therapy for genetic hepatocellular jaundice. Clin Rev Allergy Immunol 48(2-3): 243-253.

9. Yamamoto K, Sato H, Fujiyama Y, Doida Y, Bamba T (1998) Contribution of two missense mutations (G71R and Y486D) of the bilirubin UDP glycosyltransferase (UGT1A1) gene to phenotypes of Gilbert's syndrome and Crigler-Najjar syndrome type II. Biochim Biophys Acta 1406(3): 267-273.

10. Canu G, Minucci A, Zuppi C, Capoluongo E (2013) Gilbert and Crigler Najjar syndromes: an update of the UDP-glucuronosyltransferase 1A1 (UGT1A1) gene mutation database. Blood Cells Mol Dis 50(4): 273280.

11. Costa E (2006) Hematologically important mutations: bilirubin UDPglucuronosyltransferase gene mutations in Gilbert and Crigler-Najjar syndromes. Blood Cells Mol Dis 36(1): 77-80.

12. Huang CS, Tan N, Yang SS, Sung YC, Huang MJ (2006) Crigler-Najjar syndrome type 2. J Formos Med Assoc 105: 950-953.

13. Maruo Y, D’Addario C, Mori A, Iwai M, Takahashi H, et al. (2004) Two linked polymorphic mutations (A(TA)7TAA and T-3279G) of UGT1A1 as the principal cause of Gilbert syndrome. Hum Genet 115(6): 525526.

14. Costa E, Vieira E, Dos Santos R (2005) The polymorphism c.-3279T >G in the phenobarbital-responsive enhancer module of the bilirubin UDPglucuronosyltransferase gene is associated with Gilbert syndrome. Clin Chem 51(11): 2204-2206.

Your next submission with Juniper Publishers will reach you the below assets

- Quality Editorial service

- Swift Peer Review

- Reprints availability

- E-prints Service

- Manuscript Podcast for convenient understanding

- Global attainment for your research

- Manuscript accessibility in different formats

( Pdf, E-pub, Full Text, Audio)

- Unceasing customer service

Track the below URL for one-step submission https://juniperpublishers.com/online-submission.php 